\title{
EL CONTINUUM DE LAS VIOLENCIAS EN UN CONTEXTO DEL NORESTE DE MÉXICO. \\ Notas desde una experiencia de investigación social contemporánea.
}

\begin{abstract}
Luis Fernando García Álvarez
Es licenciado en Antropología por la Facultad de Filosofía de la Universidad Autónoma de Querétaro (UAQ) Se ha titulado como Maestro en Antropología Social en la Escuela Nacional de Antropología e Historia (ENAH) Actualmente, es Doctorante del Posgrado en Antropología Social en la misma institución, e investigador adscrito al Centro del Instituto Nacional de Antropología e Historia (INAH) Nuevo León antropologia.nl@hotmail.com

\section{Resumen}

El presente artículo hace referencia al continuum de las violencias que desde hace más de una década configura con agudeza la vida cotidiana de una sociedad en el noreste de México. Esto con el objetivo de mostrar algunas dimensiones sociales relevantes sobre dicho fenómeno y, por otro lado, aportar elementos que orienten la práctica etnográfica en contextos al límite producidos por la disputa entre diferentes organizaciones criminales y lo que se afrontó como una "guerra o combarte" por parte del Estado mexicano desde el 2006. En términos metodológicos, se parte de la experiencia de trabajo de campo en el contexto del Área Metropolitana de Monterrey (AMM) en el marco de un proceso de investigación social iniciado en 2010 y finalizado en 2016. Concluimos que el análisis de los procesos o fenómenos que se articulan a la producción del continuum de las violencias es fundamental para la construcción de un enfoque etnográfico que permita develar las condiciones que sostienen las violencias para generar alternativas que desmantelen su naturalización.
\end{abstract}

México

Palabras clave: violencias, trabajo de campo, etnografía, México. 


\section{INTRODUCCIÓN}

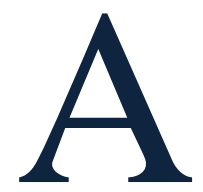

1 situarnos a unos años de realizar trabajo de campo en el noreste de México (20102016) ${ }^{1}$, hemos observado la complejidad que resulta comprender y explicar las múltiples formas en que la violencia se instala en el seno de la vida cotidiana de una sociedad o en determinadas formas de cultura. En este sentido, el tema central en el que situamos el siguiente trabajo es la práctica etnográfica en contextos de violencia (Castro y Blazquez, 2017).

Por tanto, el objetivo principal es proponer una mirada sobre el continuum de las violencias que configura con agudeza la cotidianidad de una sociedad en dicha región. Específicamente hace referencia a las violencias que se despliegan en el Área

\footnotetext{
${ }^{1}$ El noreste de México está conformado por los estados de Coahuila, Nuevo León y Tamaulipas. Limita al norte con Texas (Estados Unidos), al este con el Golfo de México, al sur con Veracruz, San Luis Potosí y Zacatecas y al oeste con Durango y Chihuahua. En términos históricos, algunas de las fuentes de información para el caso de Nuevo León durante el periodo colonial y hasta finales del siglo XIX, son útiles para comprender el proceso de etnocidio que culminó con la desaparición de los grupos nativos. Al mismo tiempo dan cuenta de la industrialización regional en el marco de un proceso de modernización y progreso económico asociado al imaginario colectivo del exterminio del indio (Farfán, Castillo y Fernández, 2001, p. 35 y 39).

${ }^{2}$ En el presente texto se utiliza la abreviatura AMM para referirse a dicho contexto; cabe decir que la conformación del AMM se constituye en los años de 1980 incluyendo 5 municipios insertos en el desarrollo urbano, industrial y demográfico de la
}

Metropolitana de Monterrey (AMM) ${ }^{2}$, con el propósito de exponer algunas dimensiones socioculturales relevantes sobre dicho fenómeno ${ }^{3} \mathrm{y}$, por otro lado, aportar elementos que orienten la práctica etnográfica en espacios donde los habitantes y los fenómenos que se estudian están inmersos en múltiples violencias (Castro, 2017), con sujetos o contextos al límite, al borde o en las lógicas de la paralegalidad (Nateras, 2015) o en conflictos, violencias y sufrimiento social (Ferrándiz, 2011).

$$
\text { Particularmente, en lugares }
$$

producidos por la disputa entre diferentes organizaciones criminales y el combate contra dichas organizaciones por parte del Estado mexicano al inicio del sexenio del Presidente Felipe Calderón Hinojosa en 2006; lo cual también se puede considerar como una coyuntura nacional partir de la

entidad neolonesa como parte del proceso de modernización nacional que tiene sus fundamentos en décadas pasadas. Actualmente, se propone un análisis de la Secretaria de Desarrollo Sustentable de Nuevo León (SEDESU), que incluye 14 municipios: Monterrey, Guadalupe, San Pedro Garza García, San Nicolás de los Garza, Santa Catarina, Escobedo, Apodaca, además de García, Juárez, El Carmen, Zuazua, Pesquería, Salinas Victoria y Santiago e incluso considera factible considerar al municipio de Cadereyta (SEDESU, 2017).

${ }^{3}$ La base etnográfica del artículo pone énfasis en la experiencia de trabajo de campo en el marco de un proceso de investigación en Antropología Social adscrito al programa de posgrado de la Escuela Nacional de Antropología e Historia (2010-2016), estudio que profundiza en el tema de las juventudes étnicas contemporáneas en contextos metropolitanos de México. 
declaración y las estrategias de seguridad del Estado en el marco de lo que se denomino como "guerra contra el narcotráfico" (Bustos, 40-47 y 79).

Por lo tanto, es necesario plantear que el continuum de las violencias vista como una perspectiva procesual, transhistórica y transcultural (Ferrándiz y Feixa, 2004, p.162) es útil para el abordaje de las singularidades en el AMM, como parte de una realidad nacional que exponencialmente muestra al Estado y su tejido social en crisis, sobre todo desde el 2006. Es decir, la debilidad presencial y funcional del Estado en un régimen democrático o una democracia incierta, como el caso mexicano, hacen más vulnerables a sus instituciones y sociedad, ante actores sociales violentos, entre los que se encuentra el crimen organizado que ha puesto en entredicho la capacidad de gobierno en las diversas geografías del México contemporáneo (Flores, 2013, p.1112).

Basta con acentuar el caso de los 43 jóvenes estudiantes de la Normal Rural Raúl Isidro Burgos de Ayotzinapa, desaparecidos en la noche del 26 y 27 de septiembre de 2014 en Iguala, Guerrero (México) en el cual se articula la actuación de diferentes fuerzas policiales, de seguridad y de organizaciones criminales en el modus operandi y la motivación de los hechos, de acuerdo con el II Informe Ayotzinapa del Grupo Interdisciplinario de Expertos Independientes (GIEI, 2015, p. 59).

Ahora bien, para lograr el objetivo señalado mostramos algunos elementos etnográficos producidos entre el 2010 y 2016 durante el trabajo de campo en el AMM y que se modulan para generar la necesidad de una perspectiva que de pistas sobre algunas certezas para el abordaje de los fenómenos que emergen en el campo de las violencias contemporáneas (Ferrándiz, 2011) y sus imbricaciones respectivas con formas determinadas de cultura producidas durante la última década en un contexto especifico del noreste de México.

En este sentido, consideramos importante re-pensar nuestra experiencia como etnógrafo para construir algunas narrativas que impliquen reconocer la reconfiguración de un contexto y una sociedad abatida por las condiciones sociales producidas por el enfrentamiento permanente e intensivo entre las organizaciones criminales y el combate por parte de las diferentes fuerzas de seguridad del Estado mexicano.

En primera instancia, coincidimos en que la violencia es una de las expresiones significativas de la cultura y las sociedades dentro del proceso histórico y social de la humanidad. Hay que mencionar además que 
Galtung (1998, p. 149), propone que el estudio de la violencia requiere necesariamente enfocarse en dos problemas: la utilización de la violencia y su legitimación. Por ello, es preciso enfatizar en todo acercamiento al tema su carácter transhistórico y transcultural, las relaciones de poder y relaciones políticas asimétricas, así como a la cultura, a las diferentes formas en que la violencia se vincula con diferentes estructuras de dominación en los ámbitos micro y macro social (Ferrándiz y Feixa, 2004, p. 160).

Es decir, la violencia no es una esencia, algo natural del ser humano, sino una construcción que se teje y se articula a través de las relaciones intersubjetivas con los otros, los objetos y las instituciones el Estado; las violencias se aprenden como códigos de comportamiento y escenarios vividos, ya sea porque se la ha sufrido, ejercido o se han presenciado (Nateras, 2015, p. 85). Por lo tanto, las violencias son parte estructurarte en la construcción del ser humano como ser cultural, de tal suerte que las violencias cotidianas que actualmente constituyen los contextos, espacios, lugares y territorios donde se sitúan los diferentes grupos sociales en México y Latinoamérica, proponen casos paradigmáticos, que necesariamente se deben comprender no como resultados de los fenómenos locales, sino en su articulación con las dinámicas globales y multidimensionales (García, 2015, p. 5-6).

Ahora bien, coincido en que más que definir el concepto de violencia desde una perspectiva substancial, la tarea es observar los fenómenos articulados a ella y que necesariamente implica hablar de violencia en plural como una diversidad de expresiones o modalidades significativas (Fragoso, 2016, p. 63; Ferrándiz y Feixa, 2004). Por ello, proponer la concepción de las violencias como un continuum:

Implica entenderlas como un proceso que se
explica en función de sus conexiones con el
espacio donde las violencias son
producidas, el agente - de cualquier
naturaleza- que las ejerce, las
circunstancias socioculturales en las que se
presentan, y la historia personal,
psicológica y social de quienes la padecen
o la practican (Fragoso, 2016, p. 64).

Con estos planteamiento iniciamos la reflexión para ubicar la realidad mexicana contemporánea en las imbricaciones que conllevan las violencias generadas dentro de un contexto, dinámicas socioculturales y actores específicos. Asimismo, consideramos que esto implica la necesidad de re-pensar las exigencias de investigación que imponen los espacios sociales emergentes configurados por las múltiples violencias producidas por la disputa entre los diferentes grupos de la delincuencia organizada por territorios 
específicos, el combate del Estado en sus distintos niveles y la búsqueda de las conexiones entre las violencias y la construcción de otras subjetividades en las distintas dimensiones de la vida cotidiana de una sociedad civil en particular.

Por tanto, la primera parte de este artículo muestra un panorama general sobre cómo se configura el AMM en términos económicos y socioculturales sobre todo a partir de la segunda mitad del siglo XX y hasta el presente año. Luego se enfoca en nuestra experiencia de trabajo de campo en distintos lugares de dicho contexto, para después referirnos a algunos acontecimientos o manifestaciones de violencia directa (Galtung, 1998) que se instalan en una cultura del terror (Bourgois, 2001) y que poco a poco trascendieron en distintas dimensiones sociales a nivel local, nacional e internacional. Para finalizar, señalamos algunas consideraciones que nos parecen relevantes para la discusión planteada y lo proponemos como un aporte al tema central que abórdanos en esta trabajo, es decir, al debate sobre la etnografía y sus límites éticos-políticos en la investigación social; discusiones iniciadas desde hace más de una década en el campo de la antropología (Castro y Blazquez, 2017; Nateras 2015; Maldonado, 2013; Ferrándiz, 2011; Blair, 2005;
Ferrándiz y Feixa, 2004; Jacorzynski, 2002; Scheper-Hughes, 1997).

Como estrategia metodológica, se hace uso de la experiencia personal como etnógrafo en el AMM durante la última década, de una revisión hemerográfica en la prensa escrita local y otros medios digitales sobre todo en los años de 2010 y 2016, entrevistas realizadas en distintos periodos de trabajo de campo y de algunas referencias bibliográficas especializadas publicadas en los últimos años en dicho tema de investigación.

\section{APUNTES SOBRE CONFIGURACIÓN CONTEMPORÁNEA DEL AMM.} LA

Con fines ilustrativos, es preciso mencionar dos periodos claves en el proceso de crecimiento de Monterrey, y su área metropolitana: a) el proceso de expansión de 1940 a finales de los años ochenta y b) el periodo que define las características actuales de dicho contexto, comprendido de 1990 hasta el nuevo milenio (Aparicio, Ortega y Sandoval, 2011, p.175). Es aquí donde podemos identificar las principales características del proceso de industrialización, urbanización y metropolización que ha transformado a la ciudad de Monterrey; además en estos periodos es donde los procesos migratorios llevan consigo flujos, movilidades y la construcción de nuevas rutas y redes sociales migrantes por parte de algunas 
poblaciones indígenas de México para asentarse definitivamente en el AMM.

Por ello, existe un predominio de la población en áreas urbanas y una disminución de los habitantes rurales en la entidad neoleonesa, una diversificación en el tamaño de las ciudades, la reorientación de los flujos migratorios, el surgimiento de migraciones de origen urbano a rurales o bien de origen metropolitano hacia destinos urbanos y rurales. Con esta dinámica se coloca como tercer lugar en el sistema urbano nacional de acuerdo con la Secretaria de Desarrollo Urbano y Obra Pública de la entidad neolonesa (SEDUOP, 2008, p. 6). Con los resultados del conteo poblacional del 2015, se estimó un total de 5, 119, 504 habitantes en la entidad, concentrados en su mayor proporción en la zona conurbada y región periférica de Monterrey (INEGI, 2015).

Debido a esta serie de procesos, se ha considerado al AMM como la de mayor competitividad en el país y dentro de las dinámicas económicas globales; destacando fundamentalmente la infraestructura, la fortaleza económica, la internacionalización, los recursos humanos y la tecnología. Por ello, se posicionó como el centro regional más importante en el noreste del país, interconectado a nivel nacional e internacional a partir de sus redes y sistemas de infraestructura, enlaces, energética, flujos productivos y financieros, siendo pivote central de la supercarretera del Tratado de Libre Comercio de América del Norte (TLCAN) entre México, Estados Unidos y Canadá (SEDUOP, 2008, p. 6).

Sin embargo, el proceso de expansión de la mancha urbana, la inversión y la especulación inmobiliaria trajo consigo la fragmentación del espacio y la polarización social. Es así que persisten las desigualdades sociales y la proliferación de asentamientos irregulares en las zonas de alto riesgo y en condiciones habitacionales precarias en los municipios metropolitanos y conurbados, mientas que el centro de la ciudad de Monterrey, redujo su población básicamente por el deterioro y transformación del uso del suelo, como ha pasado en otras ciudades de México. De esta forma, se acentuó la segregación social, geográfica y económica de la población (Aparicio, Ortega y Sandoval, 2011). Esta dinámica ocurre también como parte de los procesos de gentrificación $y$ desplazamiento que configuran las realidades urbanas de las ciudades en Latinoamérica en el contexto de la globalización contemporánea (Janoschka y Sequera, 2014).

Como parte de estas dimensiones socioespaciales se han producido, a su vez, los denominados "cinturones de miseria" que caracterizan los límites de las ciudades 
y debido a la importante migración de zonas rurales, centros urbanos y/o ciudades pequeñas al AMM se han caracterizado 53 polígonos de pobreza ubicados en diversos puntos en dicho contexto (SEDUOP, 2008, p. 39-40) $)^{4}$. Por lo tanto, el AMM se conforma por espacios que evidencian la desigualdad y segregación social, así como la fragmentación territorial, ya que además la actual expansión del área metropolitana se caracteriza por la proliferación de complejos residenciales cerrados, producto de la privatización urbana dejando a los desarrolladores inmobiliarios la dotación de infraestructura local para que los fraccionamientos que promueven se conecten a las redes municipales (Aparicio, Ortega y Sandoval, 2011).

En la consolidación de estas tendencias urbanas regionales y nacionales ha incidido, sin duda, el replanteamiento del papel multidimensional de las ciudades y metrópolis en el nuevo orden global. De

\footnotetext{
${ }^{4}$ La definición conceptual de los polígonos de pobreza está basada en las técnicas para su elaboración; se caracteriza por las variables aplicables a las unidades de observación -manzanas, viviendas hogares y sus miembros- disponibles en censos y encuestas. La unión de conceptos, variables y datos estadísticos se trasladan hacia un sistema de información geográfica, base del modelo de intervención. Es decir, los polígonos de pobreza forman parte de un modelo de intervención social para provocar o inducir un mejoramiento del entorno territorial y del bienestar de las personas que ahí residen. Por lo tanto, un polígono de pobreza es un espacio social rezagado respecto al desarrollo alcanzado por el resto de la metrópoli donde están situados. También es un espacio geográfico a donde
}

modo que existen temas y problemáticas emergentes que día a día cobran mayor preponderancia en las agendas públicas de gobierno. Tal es el caso de las violencias y la inseguridad social constitutivos en el devenir de las sociedades contemporáneas y sus territorialidades. El AMM no escapa de las actuales configuraciones nacionales e internacionales que produce el combate a las organizaciones criminales en sus múltiples dimensiones y consecuencias.

De esta manera, cobra relevancia una forma de "visibilidad" de los jóvenes de sectores populares o marginales en los espacios públicos en relación con la delincuencia y las organizaciones criminales. Sin embargo, surgen cuestionamientos que obligan a reflexionar más allá de las estigmatizaciones generadas por las imágenes e imaginarios sociales reproducidos por las instituciones y los medios de comunicación ${ }^{5}$. Por ejemplo, la prensa escrita y los noticiarios de televisión

las políticas públicas no han llegado o no lo han hecho de forma adecuada y suficiente (Martínez, Treviño y Gómez, 2009, p.9)

5 En este sentido, se puede mencionar además el papel que juegan los medios de comunicación en la promoción de la violencia social e inseguridad a partir de un estudio realizado en una ciudad fronteriza en la región noreste, esta es Matamoros, Tamaulipas en 2011. Aquí se concluye que los medios de comunicación local contribuyen a la "naturalización" de la violencia, lejos de abonar a la construcción de alternativas $u$ opciones de información y comunicación criticas y educativas que equilibren los mensajes expuestos en relación a los problemas de las violencias (Fraustro, 2014, p. 112 y 151). 
local, ya que en ámbitos más generales de la sociedad, los jóvenes resultan ser los principales sujetos en el marco de las problemáticas sociales de mayor agudeza en el AMM. Estas son la exclusión, la marginación y la pobreza, que de manera directa son relacionadas con el alcoholismo, la drogadicción, la violencia familiar y vecinal, el pandillerismo ${ }^{6} \mathrm{y}$, finalmente, con la delincuencia organizada.

De ahí que en la última década se consideró la existencia de un ejército juvenil adscrito a un grupo criminal en especifico en la ciudad de Monterrey (Martínez, 2010); hay que mencionar además que también forman una parte importante de las desapariciones defunciones que se presentan en distintos espacios del AMM, originadas al ser reclutados por los grupos u organizaciones delincuenciales antagónicas que operan en dicha área metropolitana y en la región noreste.

Reiteramos que el crimen, el miedo, la violencia y la falta de respeto por los derechos de la ciudadanía se han combinado con transformaciones urbanas para producir un nuevo patrón de segregación espacial y discriminación social en las últimas décadas (Caldeira, 2007, p. 11). En este orden, la

\footnotetext{
${ }^{6}$ En 2010 se estimó que existían cerca de 1900 pandillas en el AMM, cuyas territorialidades se situaban en 200 colonias "conflictivas", lo que en términos demográficos representaba cerca de $30 \mathrm{mil}$
}

vida cotidiana de la población en el AMM ha sido trastocada radicalmente junto con la legitimidad de las instituciones del Estado, debido a las violencias generadas por el enfrentamiento de los diferentes grupos del crimen organizado en su disputa por el control de tan importante área para el trasiego de droga hacia los Estados Unidos $\mathrm{y}$ otras formas criminales $\mathrm{y}$ delictivas asociadas (Padilla, 2017).

Ahora bien, durante la última década han ocurrido una serie de acontecimientos que marcan los altos niveles de criminalidad, violencia y terror, qua han sobrepasado el nivel local generando la atención de los medios e instituciones internacionales. Basta recordar las ejecuciones masivas que se perpetraron en salones de baile, cantinas y bares en el centro de Monterrey (como el "Sabino Gordo", "La Internacional” y “El Iguana”); Enseguida, el caso del "Casino Róyale", dejando más de cincuenta civiles en el año de 2011 (Carrizales, 2011).

En definitiva, proponemos que cualquier acercamiento pertinente a dicho contexto necesita hacer una reflexión acerca del ¿por qué Monterrey y su área metropolitana ha pasado de ser el símbolo de la modernización e industrialización

"jóvenes pandilleros" de entre 14 y 17 años en condiciones de desempleo permanente (Martínez, 2010). 
mexicana para ser un lugar marcado por la guerra entre los cárteles del narcotráfico?, ya que esta condición entró en un punto de máxima radicalidad y extremismo con los "atentados" antes mencionados, lo cual cuestiona hasta la fecha la estrategia de gobierno del ex presidente Felipe Calderón (2006-2012), quien enfrentó a organizaciones criminales dispuestas a recurrir a estas "formas de acción” y que en su momento denominaron como "narcoterrorismo". De acuerdo con un artículo publicado por la revista Proceso, uno de los grupos criminales incrementó su capacidad de respuesta ante el combate federal, con el objetivo de consolidar su poder ante los grupos rivales y el Estado mexicano (Sin autor, 2011, p. 20-21)

Este ejemplo sirve para afirmar que aunque el ejercicio de la violencia es quizá uno de los más universales, tanto sus manifestaciones como los discursos que las legitiman o las censuran, los espacios en que son toleradas o prohibidas, así como las sensibilidad respecto a sus expresiones y el modo en que éstas son visibles o se ocultan, varían de acuerdo al contexto histórico y sus sociedades (Fragoso, 2016, p. 19).

A partir de los hechos descritos en esta parte del texto, ahora proponemos desplazar la mirada y cuestionar otras dimensiones que subyacen a estas acciones perpetradas por algunos de los grupos del crimen organizado. Por ejemplo, el origen del armamento, el adiestramiento en su manejo, la capacidad y planeación de estos grupos para el ejercicio de las violencias en donde la sociedad civil no tiene cabida. Esto, sin duda, ha "generado una tristeza diaria en la capital norteña que ya no puede ser explicada como el resultado de la corrupción policial o el enfrentamiento de un cartel frente a otro. El abismo es todavía es más hondo que eso (Osorno 2012, p. 144).

Hasta el 2017, es evidente que el combarte no ha logrado la desarticulación completa de los grupos delictivos en la región noreste. Particularmente, Nuevo León ahora es denominado como la "joya el narco" por ser considero como una "zona estratégica" (Padilla, 2017) a pesar de que han realizado una serie de operativos de los cuales se desprenden la confiscación de drogas, dinero y armamentos así como detenciones, encarcelamientos, procesos judiciales, sentencias y muertes de integrantes de "células", "lideres" o "cabecillas" de los diferentes grupos del crimen organizado que operan en el AMM.

Además se han producido constantes manifestaciones públicas de civiles con inconformidades, reclamos, demandas en todos los ámbitos de la vida social, cultural, política y económica. Desde la sociedad civil, es de reconocer la posición 
crítica y de protesta sobre la consolidación de este nuevo orden de la realidad, que incluso a parir del 2010 comenzó a percibirse una suerte de "renacimiento", Se advirtió y se documentó en un conjunto de relatos gráficos desde el 2008 algunos movimientos que rompieron con el tabú del inmovilismo político en Monterrey (Peredo, 2017, p. 9).

En base al trabajo de campo realizado en el centro de la ciudad de Monterrey, proponemos que las principales calles del primer cuadro son el escenario urbano cotidiano donde se despliegan múltiples manifestaciones socioculturales. En ocasiones son acontecimientos excepcionales, extraordinarios 0 coyunturales producidos por diferentes actores sociales. Entre estas manifestaciones mencionaremos brevemente dos movilizaciones civiles a raíz de episodios de violencia directa $^{7}$, entendidos como sucesos de muerte relacionados con organizaciones criminales y la sociedad civil en su condición de "víctimas o daños colaterales" tanto a nivel local como nacional.

\footnotetext{
${ }^{7}$ De acuerdo con Galtung (1999) la violencia directa está relacionada con un desarrollo temporal, de modo que puede ser entendida como un suceso, generador de ansiedad y desesperación cuando el orden establecido se ve desafiado; pero con la posibilidad de generar un trauma individual $o$ colectivo (p. 154-155).
}

En primer lugar, el asesinato de Lucy, una estudiante universitaria que fue víctima del fuego cruzado entre grupos criminales en el centro de Monterrey en octubre de 2010; y las protestas públicas consecutivas, como formas expresivosignificativas con las cuales la sociedad civil abría el diálogo consigo misma, al tiempo que interpeló a las instituciones de seguridad y al gobierno estatal con una consigna exacta: "Ni una muerte más en Nuevo León". De igual manera, tomo relevancia la marcha organizada por el Movimiento por la Paz y la Dignidad en mayo del $2011^{8}$, una movilización nacional que en la ciudad de Monterrey adquirió un papel significativo en el campo de lo político y la lucha social por crear un contexto diferente exigiendo " justicia, dignidad y seguridad para todas y todos".

No obstante, podemos destacar que dicho contexto presenta un fenómeno social relevante relacionado con la persistencia de condiciones de desigualdad, racismo $\mathrm{y}$ discriminación por condiciones de clase, etnia, sexualidad y que su "visibilidad" en el espacio público en muchas ocasiones se asocia con prejuicios, imágenes y estigmas

\footnotetext{
${ }^{8}$ Para profundizar en el estudio de la calle, como escenario de lo púbico donde se exponen múltiples formas de habitar y significar la ciudad, véase el trabajo realizado por Farfán, García y Fernández (2015) en relación a una etnografía de la calle Morelos en el centro de la ciudad de Monterey, Nuevo León.
} 
sociales cuyas determinaciones son negativas. En los últimos años, un estudio de la Comisión Nacional para Prevenir la Discriminación, demostró que Monterrey presenta un alto índice de discriminación, una problemática cuyo fundamento responde a la diferencia de clases, entre otras condiciones sociales (CONAPRED, 2011, p. 52-65).

En este sentido, ahora buscamos enfatizar algunas de las condiciones sociales que contextualizan el continuum de las violencias a partir otros lugares etnográficos, con el interés de comprender las tensiones, conflictos y negociaciones donde las y los actores sociales están imbricados desde diferentes posicionamientos a fin de interpelar las violencias que padecen y que producen, es decir, que se construyen desde su articulación con los otros, con las instituciones del Estado y los medios de comunicación.

Sin duda, los hechos relacionados con el crimen organizado 9 en la disputa por el territorio y el mercado de la droga, lleva a la práctica de actividades con mayor

\footnotetext{
${ }^{9}$ Para profundizar en la génesis y evolución histórica del concepto de crimen organizado es preciso consultar el análisis propuesto por Flores (2013).

${ }^{10}$ En este sentido, cabe mencionar que a partir de la introducción de este nuevo modelo para procesar judicialmente a los adolescentes acusados de cometer alguna conducta contraria a la ley penal, a partir del 2008 en México éstos ya no son vistos como menores infractores, sino como personas con
}

precisión así como a la ejecución de una serie de estrategias, tácticas y mecanismos para generar violencia y terror en su búsqueda por el control y el poder.

Por tanto, podemos reconocer que Nuevo León es sólo uno de los ejemplos del involucramiento los jóvenes dentro de las redes del crimen organizado. La denominación de "halcones", "tapacalles" o "niños y jóvenes sicarios", serían algunas de las especializaciones en las cuales entran en juego un sector de los jóvenes regiomontanos. Otra serie de especializaciones en las cuales están relacionados son el comercio de piratería, así como la venta y distribución de droga o narcomenudeo. En este sentido, podemos apuntar que "en el subterráneo mundo de los negocios, el niño, el adolescente, el asesino precoz, tiene a su favor y lo saben los contratantes, la edad de la inimputabilidad" (Cajas, 2004, p. 239) ${ }^{10}$.

En efecto, podemos subrayar que fue de conocimiento nacional el hecho de que algunos grupos de jóvenes durante el 2009 y 2011 realizaron bloqueos en varias de las principales avenidas de Monterrey ${ }^{11}$,

responsabilidad penal progresiva. Es decir, ahora responden penalmente ante el Estado mexicano, aunque de forma diferenciada (Juárez, 2017, p. 25). ${ }^{11}$ A estas acciones realizadas por algunos grupos de jóvenes regiomontanos, así como otros grupos delictivos las denominaron como "Narcobloqueos" y el termino fue común alrededor de 11 meses en los titulares de los periódicos y noticieros de televisión local y nacional (Maguey, 2011). 
demandando el retiro de las fuerzas militares, quienes se mantenían de forma permanente en las calles y colonias de Monterrey y su área metropolitana como parte de un operativo nacional en varias regiones de México. Dichas protestas produjeron tensión, confrontación y conflicto directo con una otra parte de la sociedad civil y, por supuesto, con las instituciones de seguridad pública municipal, estatal y federal. El trasfondo de todo esto, en las narrativas de las instituciones de seguridad fue que dichos bloqueos fueron una respuesta directa tras la detención militar de un "líder de plaza" vinculado a una organización criminal.

El trabajo de campo realizado en este escenario, permite exponer el papel significativo que desempeñaron los medios de comunicación local, mostrando un especial énfasis en la construcción de una imagen juvenil emergente denominándolos como "los tapacalles" y, con ello, desarrollaron un importante interés tanto en la prensa escrita como en los medios de comunicación electrónicos. Además, los noticieros nacionales (como TV Azteca Noticias y Noticieros Televisa) enfatizaron estos sucesos en su agenda periodística durante varios meses. Por otra parte, una de las notas en el periódico Milenio, Diario de Monterrey en el 2009, destacó lo siguiente:
El perfil del tapacalles. La mayoría son menores de edad, con poco criterio y una socialización familiar deficiente: el vínculo con el narcotráfico. Las condiciones de pobreza y exclusión social hacen presa fácil a los jóvenes. Los cuatro bloqueos que se han realizado en la ciudad han sido en su mayoría por jóvenes de sectores populares con aspecto tipo pandillero. La vestimenta de estos jóvenes de alguna manera evidencia la procedencia de los tapacalles: pantalones holgados, camisas deportivas, tenis Converse, son parte de un estilo que brinda algunas pistas de los protagonistas de los bloqueos (MILENIO, 2009, p.7).

Otras adscripciones derivadas de los medios de comunicación e instituciones de seguridad en el AMM, los denominaron como "los tapados", refiriéndolos como un "auténtico ejercito de jóvenes desempleados que Los Zetas han sabido reclutar lenta y estratégicamente". "Ya no son pandilleros, ni mucho menos anónimos". ahora su identidad los revela como: "tapacalles de Los Zetas, narcobloqueadores" (Martínez, 2010).

La emergencia de estas imágenes juveniles estigmatizaron a un sector de jóvenes que no pertenecían necesariamente a algún grupo delincuencial; sin embargo, esta representación colocó a muchos de ellos en condiciones aún más vulnerables y con mayor desigualdad social frente a otros jóvenes y ante la sociedad local, ya que los situaron como "jóvenes albañiles, obreros o 
desempleados permanentes, habitantes de zonas marginales de la ciudad, con baja o nula escolaridad, consumidores de droga, narcotraficantes o narcomenudistas" (Martínez, 2010), asumiendo como única forma de sobrevivencia sumarse al crimen organizado.

En este punto es importante destacar que para muchos de estos jóvenes, una de las consecuencias irreversibles es la desaparición o la muerte, o en última instancia tener la experiencia de enfrentar un proceso judicial. En este sentido, podemos señalar que Reguillo (2017) planteó un análisis en base a cifras oficiales develando que "durante 2016 más de 10 mil jóvenes murieron en hechos violentos, el $30 \%$ de personas desaparecidas en el país son menores de 18 años y el $25 \%$ de los jóvenes que han pasado por un proceso penal han sido criminalizados por jueces $\mathrm{y}$ policías, sólo por su aspecto.

Respecto a este último punto, debemos resaltar que desde el 2008 se considera que en el ámbito de la justicia para adolescentes en México se ha operado una de las mayores reformas de todos los tiempos de acuerdo con los especialistas, la cual puede ser entendida en dos movimientos: por una parte, la sustitución del paradigma tutelar por el garantista y, por otra, el desplazamiento del modelo de justicia mixto por el acusatorio. Es decir, se ha generado un modelo de justicia especializado que conjuga los derechos de la infancia con el derecho penal, el cual se funda y alimenta del paradigma garantista y se realiza por medio del modelo de justicia acusatorio. Modelo que se aplica a jóvenes de entre 14 y menos de 18 años exclusivamente (Juárez, 2016, p. 21-25).

Esta reforma es de suma relevancia, ya que según los datos recabados durante el año 2015 se abrieron 10647 casos en los juzgados especializados en adolescentes, de los que el $63.6 \%$ por ciento fueron bajo el sistema escrito o mixto y $34.4 \%$ bajo el oral. En lo que corresponde a cifras por entidad federativa destaca que la mayor cantidad de asuntos de este tipo fueron en la ciudad de México con 1 106, seguido de Chihuahua con 867 y Nuevo León con 803. De acuerdo con los asuntos abiertos el tipo de conductas registradas son de un $19.3 \%$ para robo, seguido de narcomenudeo con $14.0 \% \mathrm{y}$ lesiones con $8.1 \%$ (INEGI, 2017, p. 28).

Sin embargo, desde el campo de la antropología del derecho en México, se advierten aún inconsistencias en cuanto a la defensa especializada en adolescentes, ya que como lo plantea Juárez (2017) dicha institución actualmente se encuentra desempeñando un débil posicionamiento para operar de manera efectiva en el cumplimiento del garantismo que el modelo acusatorio le confiere, ya que no sólo se 
requiere que gocen de autonomía, sino que como institución oficial reconozca y modifique efectivamente la impronta del ethos inquisitorial que el Estado mexicano ha establecido en la relación con las personas menores de edad acusadas de infringir la ley, misma que continúa reproduciendo. Finalmente, la misma autora nos obliga a pensar específicamente en el papel que desempeña la defensoría pública dentro del Sistema Integral de Justicia para Adolescentes desde un enfoque etnográfico. Es decir, el trabajo de campo puede iluminar o dar pistas sobre las características en que opera una defensoría especializada, suponiendo que casi de manera exclusiva se despliega como una defensa pasiva como única estrategia disponible en los procesos judiciales juveniles en México.

Ahora interesa señalar sólo un elemento más en el escenario de violencias en el AMM y su relación con los jóvenes indígenas. Durante el trabajo de campo, al cuestionar a un joven mixteco sobre la posible existencia de algún vínculo entre

12 Es importante subrayar que la conformación juvenil de las bandas de música de viento en la comunidad mixteca en el AMM, se concibe como un dispositivo normativo, de control y de organización comunitaria para contener las influencias relacionadas con el contexto actual de violencia, drogas y otros fenómenos relacionados (García, 2012 , p. 154). Un adulto mixteco mencionó durante la entrevista que realizamos, lo siguiente: "Nuestros chavos están mejor en las bandas de música, que ocupen su tiempo ahí (...) pues de hecho tenemos la sus pares generacionales y las problemáticas relacionas al crimen organizado, consumo de drogas u otras actividades delictivas, señaló lo siguiente:

Los chavos de la colonia no se han involucrado, se han mantenido más en las cuestiones de las tradiciones y eso les cierra un poquito las puertas para que se puedan involucrar, pero se sigue con esa visión de que no deben hacer eso y participar más en las actividades de la casa o de la colonia. Y que no deben de caer, se mantiene la idea que ya se tiene. Porque si no lo hacemos, con el tiempose va ir cambiando radicalmente, uno nunca sabe, porque en unos dos, tres o cuatro años, pudiera ver que mis propios compañeros, mis propios paisanos están ya metidos dentro de eso (E-1. joven mixteco universitario, 2012) $)^{12}$.

Para cerrar este apartado consideremos que "es indudable que la violencia permea numerosos aspectos de la vida social condicionando o determinando su dinámica (...); por lo tanto, "la violencia es un fenómeno de múltiples caras y anclajes en las distintas realidades históricas y sociales. Para descifrar su

cultura, lo que es la música tradicional, ahí estamos enseñándolos a ellos (...). Porque si los deja así abandonados (...), pues ellos también van a buscar la manera de irse o se va a drogarse o se va a cualquier cosa. Acá en este mundo hay de todo y es lo que nosotros no queremos perder, por un lado, no queremos perder la tradición que llevamos y, por otro lado, no queremos que cometan errores, que se metan a la droga y que se destruyan ellos mismos" (E-2, adulto mixteco, 2011). 
complejidad" (...), se requiere de "fragmentarla en modalidades significativas" (Ferrándiz y Feixa, 2004: 159).

Con esta intención, expusimos una serie de elementos etnográficos para aproximarnos a develar dicha complejidad y llamar la atención en la necesidad de realizar investigaciones sistemáticas y críticas sobre la configuración de este fenómeno contemporáneo en el AMM.

En dicho abordaje también se hace imprescindible generar una perspectiva que articule en diferentes niveles las modalidades de la violencia: violencia juvenil, de género, sexual, étnica, familiar, endémica, terrorista, discursiva, abierta o simbólica, corporal o psíquica, cotidiana o estructural, de alta o baja intensidad, violencia legítima o criminal, o víctimas y perpetuadores de la violencia. Entendiendo que al hablar de violencia nos referimos "a relaciones de poder y relaciones políticas (necesariamente asimétricas), así como a la cultura y a las diversa formas en que ésta se vincula con diferentes estructuras de dominación en los ámbitos micro y macro social (Ferrándiz y Feixa, 2004, p. 159).

En este marco, coincidimos en la pertinencia de construir una perspectiva teórico-metodológica así como el desarrollo de un trabajo de campo antropológico, cuyos resultados empíricos demuestren un aporte significativo en los estudios sobre las violencias contemporáneas en México y Latinoamérica. De ahí, nuestra intensión de terminar este articulo con el siguiente apartado reconociendo que una mirada antropológica sobre las violencias, implica necesariamente un enfoque procesual, relacional, históricamente situado, dinámico, con sujetos, espacios y contextos específicos (García, 2016, p. 6).

\section{LA EXPERIENCIA ETNOGRÁFICA EN EL CONTINUUM DE LAS VIOLENCIAS}

Proponemos que el abordaje de las violencias debe partir de una epistemología acertada, es decir, de pensar desde el continuum de las violencias para develar su articulación en la experiencia cotidiana de los sujetos, así como las relaciones de poder y dominación que subyace, además de alejarnos de las definiciones sustancialistas, de la pornografía de la violencia y del relativismo cultural (Scheper-Hughes y Bourgois, 2004 citados en Ferrándiz y Feixa, 2004, p. 159-160).

Esto será posible mediante la búsqueda de una transdiciplinariedad $\mathrm{y}$ transversalidad en el tratamiento de las violencias. Por ello, resulta fundamental el posicionamiento del investigador en el 
entramado de las violencias así como su definición ética, política y humanitaria en relación a los fenómenos y a los sujetos en los cuales incide su práctica antropológica. Lo anterior se puede contextualizar coincidiendo también con otros investigadores que posicionan un debate vigente de la manera siguiente:

La ola de violencia que los países latinoamericanos están experimentando desde hace varios años ha puesto en jaque gran parte de las instituciones políticas, jurídicas y sociales, incluyendo las educativas. En el caso mexicano, los problemas de inseguridad pública se han extendido a ámbitos académicos que hasta hace poco todavía parecían gozar de cierta estabilidad y tranquilidad (Maldonado, 2013, p. 124).

Por ello, ahora planteamos una reflexión acerca de las implicaciones que conlleva la práctica etnográfica en espacios emergentes que se caracterizan por el fenómeno de las violencias articuladas al crimen organizado, como el caso que hemos expuesto y que pone en juego la multidimensionalidad de relaciones que definen un proyecto antropológico de investigación y el desarrollo de un análisis pertinente en situaciones de conflicto, violencias, miedo, silencio y crimen organizado. Y donde, el riesgo, el peligro y los altos índices de inseguridad que condicionan el campo o universo de investigación, trastocan la subjetividad del investigador hasta el punto de reflexionar sobre su integridad física en el desarrollo de la práctica etnográfica dentro del trabajo de campo. Planteamos esta idea debido a la violencia directa manifestada en el espacio público metropolitano de Monterrey.

Algunos aportes relevantes desde la antropología, ya destacan el papel de la etnografía contemporánea y el trabajo de campo ante los conflictos, las violencias y el sufrimiento social. Además de llamar la atención en cuestiones sustantivas como la ética y el compromiso social del etnógrafo; y los riesgos del trabajo de campo en contextos, escenarios y lugares imbricados en una compleja densidad de configuraciones de las violencias (Castro y Blázquez, 2017; Nateras, 2015; Valenzuela; 2012, Ferrándiz; 2011; Bourgois, 2005; Ferrándiz y Feixa, 2005 y 2004; ScheperHughes, 1997, entre otros).

Así, la emergencia de temas de investigación situados en dichas particularidades exige el replanteamiento de categorías o conceptos teóricos, metodologías y estrategias de investigación, así como reflexionar sobre el posicionamiento del sujeto que investiga, es decir, desde el lugar de enunciación como etnógrafo o científico social. Esta reorientación, puede ser planteada bajo el reconocimiento de diferentes proyectos de 
investigación que se generan en otros contextos fuera de la comunidad tradicionalmente abordada en la historia de la antropología.

Por ello, es de vital relevancia la innovación y creatividad antropológica para el abordaje de escenarios emergentes de investigación, así como su trascendencia social en el seno de la indiferencia, el silenciamiento de situaciones y problemáticas de violencia, miedo y terror cotidiano en las diferentes ciudades, regiones, localidades y pueblos de México. La intención de estas líneas es lograr reconocer la especificidad que necesita el quehacer antropológico mediante el análisis del contexto, el cual genera la definición del estudio y el abordaje pertinente de acuerdo a las condiciones vitales del trabajo de campo.

Por otra parte, resulta fundamental reflexionar sobre el sentido de la investigación social en contextos de alto riesgo, de intersticios, al límite o de fronteras donde el compromiso del investigador con las problemáticas y actores sociales abordados, convierten los resultados del estudio en un texto político, ya que se inserta en un entramado de poder dentro de los sistemas socioculturales y los procesos sociales subjetivos particulares.

Es decir, la practica etnográfica relacionadas con las configuraciones de las violencias contemporáneas lleva consigo la "la necesidad de preguntarnos qué tipo de conocimientos antropológicos podemos y estamos interesados en producir y quiénes son sus principales receptores, a parte de la comunidad académica. De este modo resulta imprescindible cuestionarnos ¿qué tipo de representaciones estamos textualizando en forma de conocimiento y qué lugar ocupan nuestras narraciones en el discurso público sobre la violencia? (Maldonado, 2013, p. 137-140).

Desde este enfoque, resulta trascendente la articulación de la antropología con el campo de las violencias para re-pensar propuestas teóricas, estrategias metodológicas, implicaciones éticas y posicionamientos del etnógrafo, así como los debates académicos y políticos en los que se insertan las investigaciones, para conformar una mirada que busque una mayor comprensión de los contextos paradigmáticos, donde los ciclos y el continuum de la violencia o la violencia cotidiana son fenómenos que demuestran la complejidad constitutiva que configura espacios, culturas y sujetos concretos. Y donde el investigador, reitero, debe cuestionar-reflexionar sus implicaciones y compromisos éticos-humanitarios (Scheper-Hudges 1997; Bourgois, 2005; Wolf, 2002 y Fragoso, 2016). 
De ahí, la necesidad de desvincularnos de las visiones sustancialistas y unidimensionales que buscan de manera "tendenciosa", la comprensión y explicación de los orígenes, causas, dinámicas y consecuencias de las violencias, como el caso de los medios de comunicación y sensacionalistas o amarillistas. Otro elemento, importante en el proceso de escritura etnográfica lo propone Bourgois (2005, p. 32) considerando que a través de, fotografías desgarradoras y poética seductora, los etnógrafos se arriesgan a contribuir a una pornografía de la violencia que refuerza las percepciones negativas de los grupos subordinados a los ojos de los lectores predispuestos a ello.

En este sentido, se puede advertir la condición de que "algunos de los interrogantes que los analistas se están haciendo sobre la violencia están respondiendo más bien a sentimientos generalizados de desorden y moralidad de la vida humana, que por las dimensiones estructurales y fuerzas locales y globales que producen la violencia". De modo que no se debe perder de vista que existe la posibilidad de que "las representaciones comunes que tenemos de la violencia han influido en nuestra manera de entenderla, nuestras preguntas de análisis y también nuestra forma de relacionarnos con ella" (Maldonado, 2013, p. 130).

\section{A MANERA DE CIERRE}

Es necesario detenernos y cuestionar las condiciones vigentes donde la problemática de la violencia, la disputa entre las organizaciones criminales, su combate, las zonas de conflicto y la serie de problemáticas sociales que conlleva, configuran un contexto de alta tensión e inseguridad social. Ahí es donde la práctica etnográfica se redefine constantemente $\mathrm{y}$ donde la interacción permanente con los colaboradores de investigación reafirman una serie de preocupaciones, miedos e inseguridades producidas por dichas condiciones, ya que es imposible dejar de mirar o presenciar situaciones violentas que irrumpen radicalmente en las subjetividad de los individuos y de la sociedad local en general.

Por lo tanto, el quehacer antropológico, frente a la emergencia de nuevos escenarios y actores sociales, debe reorientar la práctica investigativa a la luz de las situaciones contemporáneas donde el compromiso, la ética profesional, el replanteamiento de conceptos, categorías y métodos es una tarea todavía aún pendiente en las agendas institucionales y centros de formación académica en antropología de 
México y/o Latinoamérica. Esta reorientación, puede ser planteada bajo el reconocimiento de diferentes proyectos de investigación generados en otros contextos fuera de la comunidad tradicionalmente abordada en la historia de la antropología, admitiendo que las violencias contextualizan los procesos de investigación etnográfica contemporáneos. Un ejemplo, son los trabajos etnográficosreflexivos reunidos por Castros y Blazquez (2017).

Por lo tanto, "el reto de la etnografía es, pues, contener el impulso de presentar una imagen saneada, y esclarecer las cadenas de causalidad que unen la violencia estructural, política y simbólica con la producción de la violencia cotidiana, que sostienen las relaciones de poder desiguales y transversal los esfuerzos de resistencia" (Bourgois, 2005, p. 32).

De esta manera, podemos aproximarnos a las "dimensiones realistas de la etnografía" que buscan "comprender la violencia desde el punto de vista de los procesos materiales y subjetivos que le otorgan sentido y significado" y, al mismo tiempo, resulta fundamental "comprender las distintas lógicas de la violencia" para construir "entornos de seguridad" mínima en los lugares donde se está realizando trabajo de campo" (Maldonado, 2013, p. 136). De ahí la importancia de generar procesos reflexivos en relación al "estar ahí", en el lugar etnográfico u antropológico, cuestionándonos constantemente sobre las implicaciones de la condición del etnógrafo en la observación participante, y en su incidencia política y social en el lugar antropológico y con los colaboradores de investigación.

Retomando el caso del área metropolitana de Monterrey y la región noreste, de ninguna manera se debe normalizar el "terror del narco," por lo cual proponemos que se debe desencarnar "el mundo del crimen" de la sociedad, rompiendo con el miedo y el silencio. Algunas de las posibilidades de acción que llevan a pensar en que "otro mundo es posible", son las alternativas de movilización y solidaridad social, las redes y propuestas de los grupos de activistas para articular las denuncias a dimensiones globales y hacer frente a la impunidad de los gobiernos, tal como lo documenta Peregrino (2017), en su narrativa visual sobre la recuperación de espacios públicos en la ciudad de Monterrey, donde cerca de 20 organizaciones civiles salieron a las calles en distintos momentos para defender los derechos fundamentales y exigir justicia $\mathrm{y}$ paz a partir de creatividad.

Consideramos que la creatividad colectiva o comunitaria es una fuente de dispositivos socioculturales para evitar la 
atomización social y la fragmentación individual frente al otro $\mathrm{y}$ modular nuevamente una vida cotidiana y pública en dicho contexto. Sin duda, la responsabilidad social y el valor moral, posibilitan evitar recluirse tras las paredes y aceptar "el mundo del narco" como una institución sólida en la sociedad. Ya que "la dignidad y la resistencia se mueven, y buscan construir otras rutas para la paz y la justicia, al mismo tiempo que exigen castigo para los responsables de tantas muertes innecesarias y terminar con la impunidad (Valenzuela, 2012, p. 221).

Finalmente, proponemos que estas ideas pueden abrir algunas pistas para contribuir en la problematización de fenómenos articulados al continuum de las violencias y lograr una comprensión que nos aproxime a generar vías o alternativas para desmantelar la naturaleza del "crimen organizado" y del cual no están exentas, las instituciones públicas y civiles, la sociedad y los que ejercemos la práctica etnográfica en contextos al límite, es decir, en contextos de continuum de violencias.

\section{Referencias}

APARICIO Moreno, Carlos Eduardo;

ORTEGA Rubí, María Estela y

SANDOVAL Hernández, Efrén. “La segregación socioespacial en

Monterrey a lo largo de su proceso de metropolización". Región y

Sociedad, vol. XXIII, núm. 52, pp. 173-207, 2011.

BLAIR, Elsa. "La violencia frente a los nuevo lugares y/o los otros e la cultura". Nueva Antropología. Tierra quemada: violencias y culturas en América latina. México. pp. 13-28, CONACULTA-INAH.

BOURGOIS, Philippe. "Más allá de una pornografía de la violencia.

Lecciones desde el Salvador”,. En: FERRÁNDIZ, Francisco y FEIXA, Carles (edits.) Jóvenes sin tregua. Culturas y políticas de la violencia, Barcelona, Anthopos, pp. 11-34, 2005.

_ The Continuum of Violence in War and Peace: Post-Cold War Lessons from El Salvador".

Ethnography, vol. 2 núm.1, pp. 5-34, 2001.

CALDEIRA, Teresa Pires do Río.

Ciudad de muros, crimen, segregación y ciudadanía en San Paulo, Barcelona, Gedisa, 2007. 
BUSTOS González, Felipe. Prácticas

periodísticas en Xalapa, Veracruz

(2004-20012). Tesis de maestría en

Ciencias Sociales. Universidad

Veracruzana, Xalapa, Veracruz.

CAJAS, Juan. El tequio y la maroma, cocaína, traqueteos y pistolocos en Nueva York. Una antropología de la incertidumbre y lo prohibido.

México,

Porrúa/CANACULTA/INAH, 2004.

CASTRO Neira, Yerko.

"Introducción". En: CASTRO Neira,

Yerko y BLÁZQUEZ, Adéle

(coords.) Micropolíticas de la

violencia. Reflexiones sobre el

trabajo de campo en contextos de

guerra, conflicto y violencia.

Cuadernos de trabajo, No5. México, pp. 4-7, 2017, Im MESO, 2017.

CASTRO Neira, Yerko y

BLÁZQUEZ, Adéle (coords.).

Micropolíticas de la violencia.

Reflexiones sobre el trabajo de campo en contextos de guerra, conflicto y violencia. Cuadernos de trabajo, No5. México, Im MESO, 2017.

CONAPRED. Encuesta Nacional sobre Discriminación en México 2010. México. CONAPRED. 2011.
FARFÁN MORALES, M. Olimpia;

CASTILLO Hernández, Jorge A. y

FERNANDEZ Areu, Ismael. "Los

Indios de Nuevo León. textos para su historia". Antropología. El Norte de México. Una mirada. México, p. 35-

39. INAH, 2001.

FARFÁN MORALES, M. Olimpia;

GARCÍA Álvarez, Luis Fernando y FERNANDEZ Areu, Ismael. "La calle Morelos: usos y apropiaciones del espacio público en el centro de Monterrey, Nuevo León". En:

Contreras, Camilo (coord.)

Monterrey a través de sus calles. una revisión desde las ciencias sociales. México, pp. 109-132, COLEFCONARTE, 2015.

FERRÁNDIZ, Francisco. Etnografías contemporáneas. Anclajes, métodos y claves para el futuro, España,

Anthopos-UAM-I, 2011.

FERRÁNDIZ, Francisco y FEIXA, Carles (edits.). Jóvenes sin tregua. Culturas y políticas de la violencia, Barcelona, Anthopos, 2005.

FERRÁNDIZ, Francisco y FEIXA, Carles. "Una mirada antropológica sobre las violencias". Alteridades. 14 (27), pp. 159-174, 2004. 
FRAGOSO Lugo, Perla O. A puro golpe. Violencias y malestares sociales en la juventud cancunense. Tuxtla Gutiérrez, Chiapas.

UNICAH:CEPHCIS-UNAM. 2016.

FRAUTRO Ortega, Jesús. "Medios de comunicación y violencia en Matamoros2. En: Zarate Ruiz, Arturo. Matamoros violento y. La ilegalidad en su cultura y la debilidad en sus instituciones. México,

COLEF, 2014.

FLORES Pérez, Carlos Antonio. El

Estado en crisis: crimen organizado y política. Desafíos para la consolidación democrática. México, CIESAS. 2013.

GALTUNG, Johan. Tras la violencia. Reconstrucción, reconciliación, resolución: afrontando los efectos visibles e invisibles de la guerra y la violencia. España, Bilbao:Gernika Gogoratuz, 1998.

GARCÍA Álvarez, Luis Fernando. Jóvenes indígenas en Contextos Metropolitanos. La construcción de lo juvenil en una comunidad mixteca en el Área Metropolitana de Monterrey, Nuevo León”. Tesis de maestría e Antropología Social. ENAH, Ciudad de México, 2012.
JUAREZ Ortiz, Guadalupe Irene. La defensa técnica especializada en adolescentes en el modelo acusatorio como reflejo del ethos inquisitorial en México, mecanoescrito inédito, 2017.

__ Reformas, procesos y

trayectorias. Análisis antropológico del proceso judicial para adolecentes, dentro del modelo acusatorio en el estado de Querétaro. Tesis doctoral en Antropología Social, CIESAS, Ciudad de México, 2016.

MARTINEZ Jasso, Irma; TREVIÑO Cantú, Jesús y GOMEZ Meza, Marco. Mapas de pobreza y rezago social. Área Metropolitana de Monterrey. Monterrey, Consejo de Desarrollo Social, 2009.

MALDONADO Aranda, Salvador. "Desafíos etnográficos en el estudio de la violencia. experiencias de una investigación". Avá. Revista de Antropología, núm. 22, pp. 123-144, 2013.

MILENIO. "El perfil de tapacalles", Milenio. Diario de Monterrey, p.7. 2009.

MUCHEMBLED, Robert. Una historia de la violencia. Del final de 
la Edad Media a la actualidad,

Madrid, Paidós, 2012.

NATERAS Domínguez, Alfredo.

Vivo por mi madre y muero por mi barrio. Significación de la violencia y muerte en el Barrio 18 y la Mara Salvatrucha, México, UAM-I y Tiran Blanch Humanidades, 2015.

OSORNO, Diego Enrique. "Lo regio y lo Róyale: de cuerpo estatal a policía regia". Antropología, $\quad N^{\circ} 94$, Nueva Época, México, INAH, pp. 144-146, 2012.

SEDUOP. Plan de Desarrollo Urbano de la Zona Metropolitana de Monterrey, México, Secretaría de Desarrollo Urbano y Obras Públicas (SEDUOP), 2008.

SCHEPER-HUDGES, Nancy. La muestre sin llanto, Violencia y vida cotidiana en Brasil, Barcelona, Ariel, 1997.

SIN AUTOR, 2011. "Monterrey: bombas para el Ejercito". Proceso, núm. 1925, pp.20-21.

VALENZUELA Arce, José Manuel. Sed de mal. Feminicidio, jóvenes y exclusión social, México, COLEFUANL-CONACYT, 2012.
WITOLD, Jacorzynski. Estudios sobre las violencias. Teoría y práctica. México. CIESAS-Miguel Ángel Porrúa. 2002.

WOLF, Eric. "Ciclos de violencia: la antropología de la paz y la guerra". En: Jacorzynski WITOLD (coord.), Estudios sobre la violencia: teoría y práctica, México, CIESAS- Miguel Ángel Porrúa, pp. 39-57, 2002.

\section{RERENCIAS EN LA INTERNET}

GARCÍA Álvarez, Luis Fernando. "Presentación. Juventudes y violencias en Latinoamérica".

Revista Nuestramérica, 4 (8), pp. 510. 2016. Recuperado de http://revistanuestramerica.cl/ojs/inde x.php/nuestramerica/article/view/29

GIEI. II Informe Ayotzinapa. Avances y nuevas conclusiones sobre la investigación, búsqueda y atención a las víctimas. sobre la búsqueda. México, Grupo Interdisciplinario de Expertos Independientes. 2015.

Recuperado de http://docs.wixstatic.com/ugd/3a9f6f _7e190b69e1b14980add30c4aa015d2 e8.pdf 
INEGI. Censo Nacional de

Impartición de Justicia Estatal 2016.

México. INEGI. 2017. Recuperado de

http://www.beta.inegi.org.mx/app/bib lioteca/ficha.html?upc $=70282509158$ 3

Encuesta Intercensal 2015.

Nuevo León, México. INEGI.

Recuperado de

http://www.beta.inegi.org.mx/app/are asgeograficas/?ag=19\#tabMCcollaps e-Indicadores

SEDESU. Presentación de la Estrategia de Desarrollo Urbano del Estado de Nuevo León. Monterrey, 2017. Recuperado de http://www.nl.gob.mx/publicaciones/ estrategia-de-desarrollo-urbano-delestado

REGUILLO, Rossana. "La condición juvenil en México y los contextos de violencia e inseguridad". Foro Nacional de Jóvenes, Justicia y Seguridad en México, San Luis Potosí, México. 2017. Recuperado de https://www.youtube.com/watch?v=d 6C4mbYdTt0;

Véase también:

CONSULTA HEMEROGRÁFICA ON LINE

CARRIZALES, David. 2011."Al menos 53 muertos en ataque a casino de Monterrey". La Jornada, Recuperado de http://www.jornada.unam.mx/2011/0 8/26/politica/002n1pol

MARTÍNEZ, Sanjuana. 2010. "Los tapados, ejercito juvenil de Los Zetas, se vengaron de una sociedad que los margina". La jornada.

Recuperado de http://www.jornada.unam.mx/2010/0 6/10/politica/009n1pol

MAGUEY, Hugo. "Narco Bloqueos: 11 meses de miedo". Animal político. 2011. Recuperado de http://www.animalpolitico.com/2011/ 02/narcobloqueos-11-meses-demiedo/

PADILLA, Jesús. 2017. "Nuevo León. la joya del narco". Reporte Índigo. Recuperado de https://www.reporteindigo.com/repor te/crimen-organizado-violencianarco-carteles-plaza-droga/ 
E-1. Joven mixteco universitario, San

Nicolás de los Garza, Nuevo León.

2012.

E-2, Adulto mixteco, Juárez, Nuevo

León. 2011. 